\title{
Costochondral graft with green-stick fracture used in reconstruction of the mandibular condyle: Experience in 13 clinical cases
}

\author{
Laura Villanueva-Alcojol, Florencio Monje-Gil, Raúl González-García, Carlos Moreno-García, Herminia \\ Serrano-Gil, Óscar Maestre-Rodríguez, Luis Ruiz-Laza, Damián Manzano-Solo de Zaldivar, Jesús Mateo- \\ Arias
}

Department of Oral and Maxillofacial Surgery, Infanta Cristina University Hospital. Badajoz

Correspondence:

C/ Fernando Sanchez Sampedro, 2,2A, 06003, Badajoz, Spain,

laurivillanueva@hotmail.com

Received: $31 / 12 / 2008$

Accepted: 20/05/2009

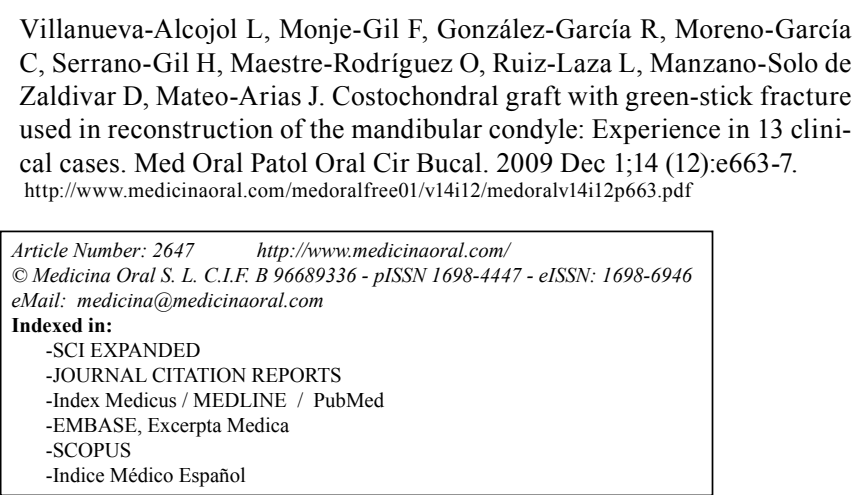

\begin{abstract}
Since its publication in 1920 by Gillies, costochondral grafts have been used by surgeons to replace an injured mandibular condyle and to reconstruct the temporomandibular joint. This procedure is currently applied in cases of congenital dysplasia, developmental defects, temporomandibular ankylosis, neoplastic disease, osteoarthritis and post-traumatic dysfunction. Over the years, various procedures for the reconstruction with this type of graft have been described. In 1989, Mosby and Hiatt described a technique for setting the graft securely, reducing the space between the graft and the mandibular area. In 1998, Monje and Martín-Granizo developed a variation of this method, enabling a precise adaptation of the costochondral graft to the remaining mandibular ramus. The aim of this study is to evaluate the functional and anatomic results of the costochondral graft treatment by green-stick fracture for reconstruction of the TMJ in the 10 years following the description of this technique. We carry out a retrospective study of thirteen cases of temporomandibular pathology (tumors, ankylosis and hypoplasia) treated during a period of ten years from 1998 to 2008. In all these cases, the technique described by Monje and MartínGranizo was used: removal of the sixth rib, fixation to a titanium mini-plate using screws, making an internal corticotomy in order to obtain a green-stick fracture of the outer cortex, providing adequate adaptation of the graft to the mandibular ramus. The graft was then set in place, attaching it with titanium screws. This technique was successful in achieving optimal ossification, a good interincisal opening and satisfactory cosmetic results. In conclusion, according to our experience, the green-stick fracture for the adaptation of costochondral grafts to the remaining mandibular ramus has presented outstanding results in the surgical treatment of temporomandibular pathology.
\end{abstract}

Key words: Costochondral graft, autologous grafts, TMJ reconstruction, open TMJ surgery, temporomandibular pathology. 


\section{Introduction}

The reconstruction of the temporomandibular joint (TMJ) is one of the most complex fields within Oral and Maxillofacial Surgery. The objectives of this reconstruction are well defined and include the restoration of the three-dimensional morphology and mandibular function, decreasing the patient's symptoms and limitations, and prevention of disease progression (1). To achieve these objectives, various surgical techniques have been used with autogenous and alloplastic materials (2). Among the autologous materials, costochondral grafting is the most adaptable due to its original dimensions. The benefits described by MacIntosh (3) are its biological compatibility, ease of use, accessibility, functional adaptability, versatility, and minimal additional morbidity for the patient. Due to the incorporation of growth centers in the transplant, the potential for growth of the costochondral graft makes it an ideal application for reconstructing TMJ in children (4-6). Among some of the possible complications described, we highlight the risk of fracture of the graft, infection, partial or total reabsorption of the graft, morbidity in the donor area, the graft's variable capacity for growth, and the possible recurrence of ankylosis (7-9).

Based on the studies published by Gillies in 1920, this type of graft has been used to replace an injured mandibular condyle, in TMJ reconstruction. This procedure is currently applied in cases of congenital dysplasia, developmental defects, temporomandibular ankylosis, neoplastic disease, osteoarthritis and post-traumatic dysfunction $(10,11)$. Various adaptation techniques for the reconstruction with this type of graft have been described throughout the years. In 1989, Mosby and Hiatt (12) described a technique for setting the graft securely, reducing the space between the graft and the mandibular area. In 1998, Monje and Martín-Granizo (13) developed a variation of this method, making a green-stick fracture of the costochondral graft, allowing for the precise adaptation of the graft to the remaining mandibular ramus.

The aim of this study is to evaluate our experience with the use of the costochondral graft by a green-stick fracture for the reconstruction of the TMJ, in the 10 years following the description of this technique.

\section{Material and Method}

Over a period of 10 years (1998-2008), a retrospective study was performed on a serie of 13 patients with temporomandibular pathology which required condylar resection and reconstruction with a costochondral graft. This group of patients consists of 8 males and 5 females, with the average age being that of 18.6 years (range: 9-38). The pathology of the TMJ was varied, including the following diagnoses: condylar hypoplasia (3 cases), articular bone ankylosis (3 cases), tumorous aetiology
( 2 cases of osteochondroma and 1 case of malignant neoplasm), idiopathic condylar lysis (2 cases), congenital deformities of the mandible (1 case) and acquired deformities ( 1 case). In 4 cases, the pathology was bilateral, with a total of 17 reconstructions performed by costochondral grafting. All of them were performed using the technique described by Mosby and Hiatt (12) and later modified by Monje and Martín Granizo (13). All patients were followed up closely with clinical and radiological evaluations over a period of time ranging between 3 months and 10 years.

\section{Surgical Technique:}

Once the right sixth rib (sixth and seventh in bilateral cases) is harvested using a submammarian approach (measuring the cartilaginous portion between 5 and 10 $\mathrm{mm}$ and the portion of the bone $40-60 \mathrm{~mm}$ ), the graft is attached to mini-plates using titanium screws. An internal corticotomy is then made, curving the graft in order to obtain a green-stick fracture of the outer cortex and providing the convexity and proper adaptation of the graft to the remaining mandibular ramus. Finally, the graft is set in place (Fig. 1), making sure it is aligned correctly, and fastening it with titanium screws.

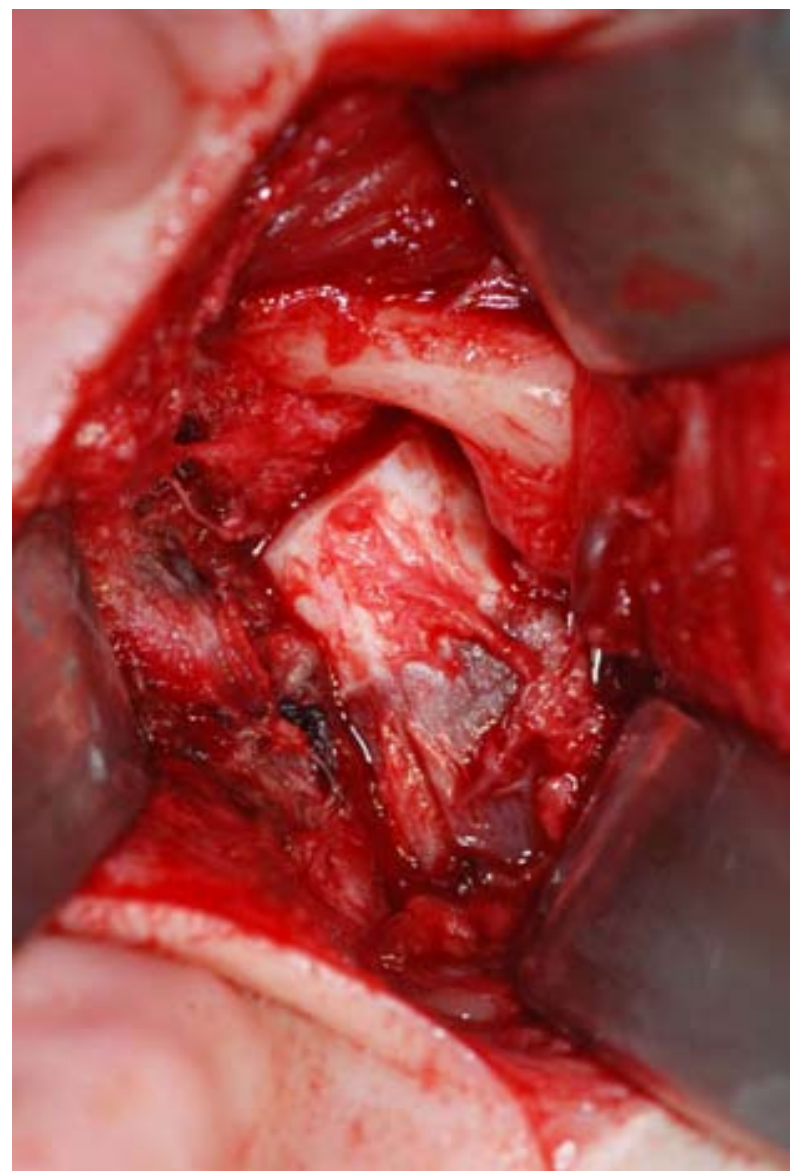

Fig. 1. Pre-auricular incision showing a costochondral graft after its placement and adaptation to the remaining mandibular ramus. 


\section{Results}

This technique was successful in all cases (Table 1), achieving optimal ossification without unwanted movement of the graft, as was revealed in the radiological tests (plain X-ray) (Fig.2) and computerized tomography (CT)). From a functional standpoint, a good oral aperture and decrease in dietary restriction was achieved. The maximum interincisal opening (MIO) increased in 13 patients, with an average increase of $11.6+/-6.75 \mathrm{~mm}$. Moreover, the aesthetic results were satisfactory, with growth of the graft commensurate with the growth of the patient (Fig.3). An evaluation of the post-operative reviews showed an improvement in facial symmetry and all patients reported satisfaction with the results. As far as complications, a case of pneumothorax was observed, which required the placement of a thorax tube, which produced a favorable outcome and progress. In one case, facial paralysis was observed in the immediate postoperative period, with spontaneous recovery during follow-up. Two patients presented a local infection, and

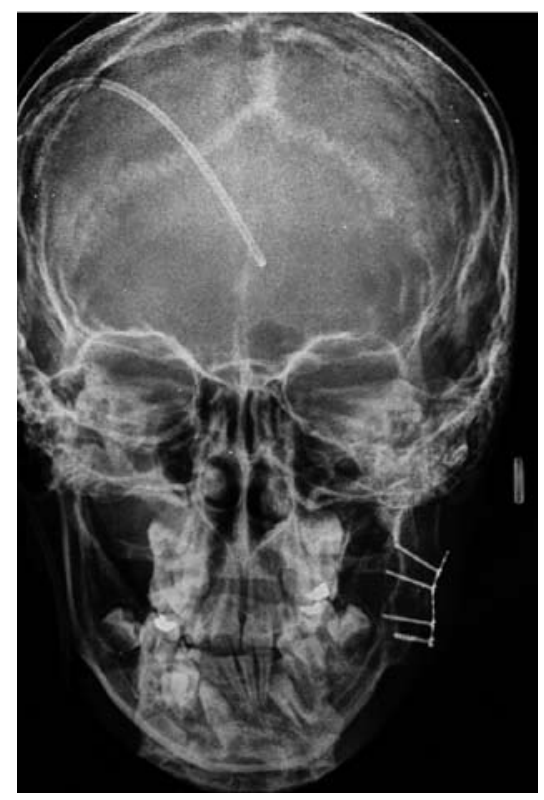

Fig. 2. Simple x-ray showing the adaptation of the graft to the condylar defect in immediate post-operative state.

Table 1. List of patients treated using the placement of a costochondral graft with green-stick fracture.

\begin{tabular}{|c|c|c|c|c|c|c|c|c|}
\hline & SEX & AGE & DIAGNOSIS & LOCATION & $\begin{array}{l}\text { PRE- } \\
\text { MIO }\end{array}$ & $\begin{array}{l}\text { POST- } \\
\text { MIO }\end{array}$ & $\begin{array}{l}\text { POSITION } \\
\text { OF GRAFT }\end{array}$ & COMPLICATIONS \\
\hline 1 & M & 33 & $\begin{array}{l}\text { OSTEOCHON- } \\
\text { DROMA }\end{array}$ & LEFT & 15 & 30 & OPTIMAL & FACIAL PARALYSIS \\
\hline 2 & M & 12 & $\begin{array}{l}\text { JOINT ANKY- } \\
\text { LOSIS }\end{array}$ & LEFT & 5 & 34 & OPTIMAL & NO \\
\hline 3 & M & 14 & $\begin{array}{l}\text { JOINT ANKY- } \\
\text { LOSIS } \\
\end{array}$ & BILATERAL & 16 & 23 & OPTIMAL & $\begin{array}{l}\text { RIGHT PNEUMOTHO- } \\
\text { RAX }\end{array}$ \\
\hline 4 & M & 12 & $\begin{array}{l}\text { MALIGNANT } \\
\text { NEOPLASM }\end{array}$ & RIGHT & 20 & 31 & OPTIMAL & NO \\
\hline 5 & M & 12 & $\begin{array}{l}\text { ACQUIRED } \\
\text { DEFORMITY }\end{array}$ & LEFT & 26 & 30 & OPTIMAL & NO \\
\hline 6 & M & 11 & $\begin{array}{l}\text { CONDYLAR } \\
\text { HYPOPLASIA }\end{array}$ & LEFT & 20 & 25 & OPTIMAL & NO \\
\hline 7 & M & 38 & $\begin{array}{l}\text { OSTEOCHON- } \\
\text { DROMA } \\
\end{array}$ & RIGHT & 16 & 20 & OPTIMAL & NO \\
\hline 8 & M & 9 & $\begin{array}{l}\text { CONDYLAR } \\
\text { HYPOPLASIA }\end{array}$ & LEFT & 20 & 32 & OPTIMAL & NO \\
\hline 9 & M & 9 & \begin{tabular}{|l|} 
CONDYLAR \\
HYPOPLASIA \\
\end{tabular} & LEFT & 34 & 50 & OPTIMAL & NO \\
\hline 10 & M & 15 & $\begin{array}{l}\text { CONGENI- } \\
\text { TAL DEFOR- } \\
\text { MITY }\end{array}$ & LEFT & 18 & 26 & OPTIMAL & LOCAL INFECTION \\
\hline 11 & M & 21 & $\begin{array}{l}\text { JOINT ANKY- } \\
\text { LOSIS } \\
\end{array}$ & BILATERAL & 8 & 27 & OPTIMAL & LOCAL INFECTION \\
\hline 12 & M & 34 & $\begin{array}{l}\text { IDIOPATHIC } \\
\text { CONDYLAR } \\
\text { LYSIS } \\
\end{array}$ & BILATERAL & 21 & 33 & OPTIMAL & NO \\
\hline 13 & M & 22 & $\begin{array}{l}\text { IDIOPATHIC } \\
\text { CONDYLAR } \\
\text { LYSIS }\end{array}$ & BILATERAL & 21 & 30 & OPTIMAL & NO \\
\hline
\end{tabular}



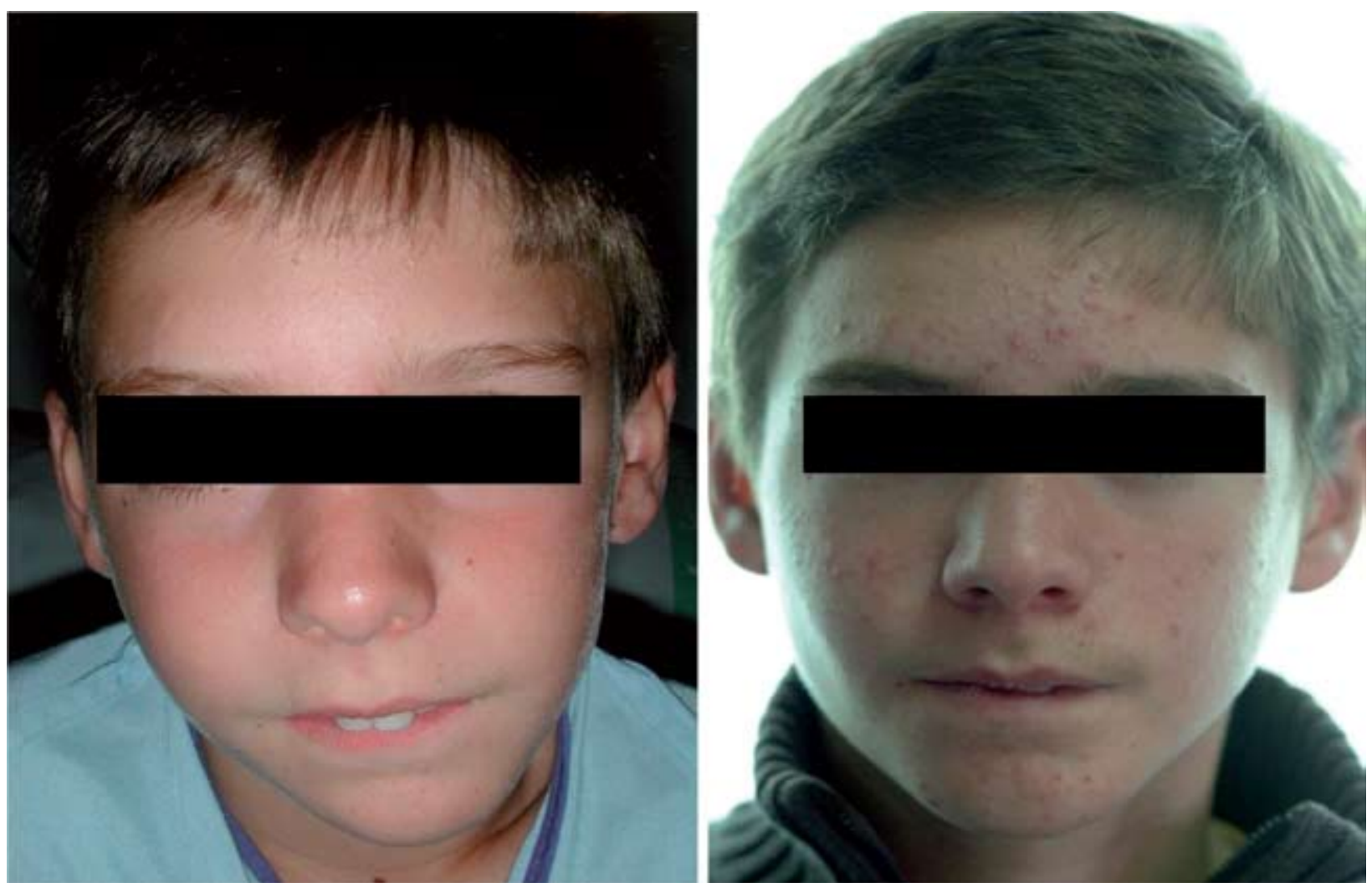

Fig. 3. a) Pre-operative image of a 9-year-old boy diagnosed with condylar hypoplasia on the left side, showing some facial asymmetry with chin deviation to the left; b): Same patient 2 years After surgery. The aesthetic result is optimal, with an almost complete facial symmetry.

in both cases they were treated with conservative antibiotics, without loss or partial reabsorption of the graft. None of the 13 cases presented hyper- or hypo-growth of the graft, as shown by measurements made on the orthopantomography requested in the immediate postoperative period and at 3,6 , and 12 months, as well as during the annual reviews.

\section{Discussion}

Because of the anatomical and biological characteristics similar to the mandibular condyle, the costochondral graft has become the most versatile autologous tissue to reconstruct the TMJ. It is logical to think that the ideal graft is one that fulfills its function in a manner similar to the original tissue. The costochondral graft consists of an autogenous material that is equipped with an articular cartilage surface that can resemble the mandibular condyle, and it has the ability to adapt and remold itself in response to joint function. In addition, since a large proportion of patients requiring condylar replacement are young and still in the process of growing, it is necessary to allow for the possibility of an appropriate degree of mandibular growth at the time of making a proper surgical plan.

After its introduction in 1920, the use of costochondral grafts in TMJ reconstruction for pediatric patients has become very popular. Because severe TMJ deformities typically affect both the bone and cartilage of the joint, this graft allows the restoration of both components. With its bone and cartilage, costochondral grafts will provide diverse populations of germ cells with an inherent growth potential, providing adequate functioning despite the lack of a disk, and also maintaining development capacity, making this an ideal graft for use in condylar reconstruction in pediatric patients. In regards to this aspect, one of the main disputes is the lack of predictable growth. In assessing the growth of the graft in eight adolescent patients, Guyuron and Lasa (14) observed growth of the graft in four $(50 \%)$ of the patients, hypo-growth in one patient and normal growth in three. In addition, three cases of postoperative ankylosis were observed, although it should be noted that these authors took a large amount of cartilage $(15-20 \mathrm{~mm})$. In a study on children, Ko and Huang (5) observed hyper-growth in 7 of the 10 patients studied. Other authors, such as Lata et al. and Siavosh et al. $(15,16)$, also refer to cases of excessive growth of the graft. In a study of 26 patients, Perrot et al. (17) observed three cases of lateral overgrowth. The findings of hypo-growth would support the theory that defends the existence of a primary growth center of the condyle, although this could be complemented by the adaptive growth of the condyle in response to the functional matrix. It appears that the 
highest growth rate would occur about 2 years after the placement of the graft and would follow a slow and irregular pattern, not a linear pattern. This was demonstrated by Mulliken et al. (18), based on tele-radiograph measurements of 17 patients who were still in the process of growing. Therefore, it is assumed that the amount of cartilage included in the graft might influence the pattern of growth. It thus seems logical to conclude that a greater need for growth (patients operated on before 10-11 years of age) requires a greater amount of cartilage. By contrast, in patients in the phase of growth after puberty or in adults, the minimum amount of cartilage should be used and only that necessary to stimulate growth and avoid disruption of the costochondral joint. In the group of patients studied, we have not observed any cases of hyper-growth in adults or children, having standardized the amount of cartilage to be used to approximately $5-10 \mathrm{~mm}$, tending to be a smaller amount the older the patient is.

As for the surgical technique used, many different methods have been described. As far as the method of attaching the graft to the mandible, we believe that the "green stick" fracture technique is a valuable aid in the alignment of the rib curvature to the mandible, as it allows some flexibility in the rib graft, making it possible to obtain a concavity that is suitable for each particular case. This provides a large contact area between the graft and the mandible, which streamlines the ossification process. The subsequent fastening of the graft in place using titanium mini-plates and bicortical screws provides greater rigidity and stability to the graft and allows a rapid postoperative mobilization and physiotherapy. Moreover, this technique always allows for the easy removal of the rib graft on the right side, decreasing the risk of damage to the pericardium during the procedure and decreasing the likelihood of confusing the postoperative discomfort with a cardiogenic type of pain. Other authors have questioned whether this change provides real advantages as far as reducing the risk of pericardial damage (19). The truth is that, in our experience, removal of the costochondral graft from the right side makes it almost impossible for complications of this nature to occur.

In regards to the case of facial palsy that occurred in the immediate postoperative period, it should be noted that this complication is attributable to the surgical manipulation, as opposed to any problem with the technique itself. With respect to other autologous grafts, the advantages of the costochondral graft are that there is a low incidence of complications and morbidity at the donor site, adaptability to the mandibular ramus and incorporation of a head of cartilage tissue that promotes the morphological and functional adaptation and reduces the future risk of ankylosis. Moreover, despite being a non-vascularized graft, the costochondral graft seems to have little tendency towards reabsorption, and in numerous occasions, it even gets bigger and resilient over time, sometimes compromising the final result due to the excessive length of the ascending mandibular ramus (7). When comparing the costochondral graft with that of the sternoclavicular graft, the latter requires a more complex surgery and presents higher morbidity at the donor site (2). Approximately $10 \%$ of clavicular fractures have been described, over $50 \%$ of which require open reduction (20).

In conclusion, according to our experience, the use of costochondral grafts for the reconstruction of the mandibular condyle using the green-stick fracture technique provides optimal results in the surgical treatment of temporomandibular pathology.

\section{References}

1. Mercuri LG. The use of alloplastic prostheses for temporomandibular joint reconstruction. J Oral Maxillofac Surg. 2000;58:70-5.

2. Vasconcelos BC, Bessa-Nogueira RV, Cypriano RV. Treatment of temporomandibular joint ankylosis by gap arthroplasty. Med Oral Patol Oral Cir Bucal. 2006;11:E66-9.

3. MacIntosh RB. The use of autogenous tissues for temporomandibular joint reconstruction. J Oral Maxillofac Surg. 2000;58:63-9.

4. Ware WH, Brown SL. Growth centre transplantation to replace mandibular condyles. J Maxillofac Surg. 1981;9:50-8.

5. Ko EW, Huang CS, Chen YR. Temporomandibular joint reconstruction in children using costochondral grafts. J Oral Maxillofac Surg. 1999;57:789-98.

6. Posnick JC, Goldstein JA. Surgical management of temporomandibular joint ankylosis in the pediatric population. Plast Reconstr Surg. 1993;91:791-8.

7. Ohara K, Nakamura K, Ohta E. Chest wall deformities and thoracic scoliosis after costal cartilage graft harvesting. Plast Reconstr Surg. 1997;99:1030-6.

8. Link JO, Hoffman DC, Laskin DM. Hyperplasia of a costochondral graft in an adult. J Oral Maxillofac Surg. 1993;51:1392-4.

9. Saeed NR, Kent JN. A retrospective study of the costochondral graft in TMJ reconstruction. Int J Oral Maxillofac Surg. 2003;32:606-9.

10. MacIntosh RB, Henny FA. A spectrum of application of autogenous costochondral grafts. J Maxillofac Surg. 1977;5:257-67.

11. Lindqvist C, Pihakari A, Tasanen A, Hampf G. Autogenous costochondral grafts in temporo-mandibular joint arthroplasty. A survey of 66 arthroplasties in 60 patients. J Maxillofac Surg. 1986;14:143-9. 12. Mosby EL, Hiatt WR. A technique of fixation of costochondral grafts for reconstruction of the temporomandibular joint. J Oral Maxillofac Surg. 1989;47:209-11.

13. Monje F, Martin-Granizo R. The "green-stick" fracture technique for adaptation and fixation of costochondral grafts. J Oral Maxillofac Surg. 1998;56:103-5.

14. Guyuron B, Lasa CI Jr. Unpredictable growth pattern of costochondral graft. Plast Reconstr Surg. 1992;90:880-6.

15. Lata J, Kapila BK. Overgrowth of a costochondral graft in temporomandibular joint reconstructive surgery: an uncommon complication. Quintessence Int. 2000;31:412-4.

16. Siavosh S, Ali M. Overgrowth of a costochondral graft in a case of temporomandibular joint ankylosis. J Craniofac Surg. 2007;18:1488-91. 17. Perrott DH, Umeda H, Kaban LB. Costochondral graft construction/reconstruction of the ramus/condyle unit: long-term follow-up. Int J Oral Maxillofac Surg. 1994;23:321-8.

18. Mulliken JB, Ferraro NF, Vento AR. A retrospective analysis of growth of the constructed condyle-ramus in children with hemifacial microsomia. Cleft Palate J. 1989;26:312-7.

19. Monje F, Martin-Granizo R. The "green-stick" fracture technique for adaptation and fixation of costochondral grafts. J Oral Maxillofac Surg. 1998;56:103-5. 